\title{
Decarbonization and Circular Economy in the Sustainable Development and Renovation of Buildings and Neighbourhoods
}

\author{
Pilar Mercader-Moyano ${ }^{1, *(\mathbb{D})}$ and Paula M. Esquivias ${ }^{2, *(\mathbb{D})}$ \\ 1 Departamento de Construcciones Arquitectónicas I, Escuela Técnica Superior de Arquitectura, \\ Universidad de Sevilla, Avenida de Reina Mercedes n², 41012 Seville, Spain \\ 2 GIR Termotecnia, Departamento de Ingeniería Energética y Fluidomecánica, Universidad de Valladolid, \\ Paseo del Cauce n ${ }^{\circ}$ 59, 47011 Valladolid, Spain \\ * Correspondence: pmm@us.es (P.M.-M.); paula.esquivias@uva.es (P.M.E.)
}

Received: 21 September 2020; Accepted: 22 September 2020; Published: 24 September 2020

\begin{abstract}
In recent years, the building sector has been turning towards intervening in the existing city building stock. In fact, it is generally accepted that the refurbishment of buildings and the urban regeneration based on sustainability must form the axis of reformulation of the building sector. Nowadays, achieving sustainable urban development inevitably involves improving existing buildings, thereby preventing the need for city growth, and for the emptying of established neighbourhoods. Furthermore, considering the whole life cycle, it is well known the great amount of greenhouse emissions derived from the construction sector, so in order to reach a decarbonized society it is important to provide eco-efficient construction materials and solutions, adding the principles of circular economy and resource efficiency. The articles of this special issue show different aspects to be considered in order to reach a decarbonized and circular building stock.
\end{abstract}

Keywords: circular economy; decarbonization of construction sector; refurbishment of buildings; neighbourhood regeneration; eco-efficient construction solutions; construction and waste management; indoor environmental quality; resource efficiency

\section{Special Issue "Decarbonization and Circular Economy in the Sustainable Development and Renovation of Buildings and Neighbourhoods"}

In recent years, the building sector has been turning towards intervening in the existing city building stock. In fact, it is generally accepted that the refurbishment of buildings and urban regeneration based on sustainability must form the axis of reformulation of the building sector. At present, achieving sustainable urban development inevitably involves improving existing buildings, thereby preventing the need for city growth, and for the emptying of established neighbourhoods. Furthermore, considering the whole life cycle, the great amount of greenhouse emissions derived from the construction sector is well known; thus, in order to reach a decarbonized society, it is important to provide eco-efficient construction materials and solutions, adding the principles of circular economy and resource efficiency.

Therefore, the theme of this Special Issue is "Decarbonization and Circular Economy in the Sustainable Development and Renovation of Buildings and Neighbourhoods" in response to the objectives not only raised at Horizon 2020 but by all the people who seek a more sustainable world. This Special Issue of Sustainability focuses on, but is not limited to:

- Obtaining an overview of the environmental problems that arise from construction activity, focusing on refurbishment as an alternative to the current crisis in the construction sector, as well as on actions designed to minimize environmental effects on the environment; 
- Searching for new alternatives to conventional construction solutions that minimize the environmental impact of the construction activity, improve indoor environmental quality of buildings, build or refurbish, always from a rentable and optimal cost in time, and implement a circular economy and an efficient resource and waste management;

- Minimizing the consumption of material resources, energy consumption and $\mathrm{CO}_{2}$ emissions in construction and looking for the proper management of construction and demolition waste and the opportunities for their recycling and reuse;

- Sustainable planning and urban development, for an ordered and sustainable growth.

\section{Background and Contents}

The European Union (EU) is committed to establish a sustainable, competitive, secure and decarbonised energy system [1]. Furthermore, the European Green Deal [2] boosts the efficient use of resources in order to get a clean and circular economy.

Buildings have a capital importance in both communications as the building sector in the European Union represents around $36 \%$ of greenhouse emissions, $40 \%$ of the final energy consumption, $50 \%$ of extracted materials, $30-50 \%$ material resource use, $21 \%$ of total water abstracted and is responsible for over $35 \%$ of the EU's total waste generation with very significant life cycle impacts, particularly associated with extraction and processing stages [1-6].

Decarbonization means a decrease in the specific amount of carbon $\left(\right.$ or $\left.\mathrm{CO}_{2}\right)$ emitted per unit of primary energy consumed. In the building sector, decarbonization can be achieved through the energy efficiency measures focused on reducing the energy demand, reducing the energy consumption and increasing the use of low-carbon technologies, such as renewable energy sources. Decarbonization in the building sector involves the materiality of the built environment throughout their whole life cycle, users' energy habits and the performance and efficiency of the building and neighbourhood systems [4].

A circular economy is one "that is restorative and regenerative by design and aims to keep products, components and materials at their highest utility and value at all times" [7]. In a circular economy, waste and resource use are minimised, and when a product reaches the end of its life it is used again to create further value [8]. In the building sector, the circular economy is applied by closing water, energy and material loops, so design for disassembly has a central role and promotes buildings, construction materials and products to be intentionally designed for material recovery, value retention and meaningful next use $[9,10]$.

In this context, the new Circular Economy Action Plan [5] promotes circularity principles throughout the lifecycle of buildings in order to increase the material efficiency and reduce the climate impacts. These goals are aligned to the 'Renovation Wave' initiative [11] as around $60 \%$ of the current EU's buildings were built under limited or non-existent energy efficiency requirements $[12,13]$ so they require a partial or total refurbishment in order to fulfil the EU's Energy Efficiency objectives for $2050[12,14]$. Furthermore, the current inefficient building stock is at the base of the energy poverty that around 50 million Europeans suffer [2], affecting their comfort, sanitation and living conditions.

Energy renovation strategies of social housing are addressed in the article written by Belinda López-Mesa, Marta Monzón-Chavarrías and Almudena Espinosa-Fernández [15]. The two studied strategies are compared based on the regulation compliance, the energy use, the emissions reduction, the thermal comfort and the cost-effectiveness of the measures. The results show that renovating the whole building with efficient solutions, including external insulation for existing brick-facing walls, and drawing up coordination plans in order to guarantee a coordinated new image of the residential estates is the best strategy, achieving a $69 \%-79 \%$ reduction of $\mathrm{CO}_{2}$ emissions and a $75 \%-97 \%$ reduction of heating use, as well as being the only one capable of transforming these buildings into nearly zero energy buildings (nZEBs).

One example on reducing energy consumption by implementing low-carbon technologies is exposed by Eloy Velasco-Gómez, Ana Tejero-González, Javier Jorge-Rico and F. Javier Rey-Martínez [16]. 
Evaporative cooling systems are energy-efficient, cost-effective and environmentally friendly solutions for cooling the indoor environment by evaporating water in dry air. It is a technology that replicates a natural process with a low energy consumption, so it can substitute, improve the performance of, or complement conventional mechanical compression cooling systems. The system depends on the wet surface in contact with the air, so the authors have designed a cooling pad that enables maximum wetted surface with minimum pressure drop so it improves the currently high efficiency of the system.

However, decarbonising the building stock must look beyond the energy consumption during the use phase of the buildings. The energy used in the manufacture of construction product and during the construction process of the building also has an important role. Manufacturing construction products represents $5-10 \%$ of total energy consumption in the EU [17] and the greenhouse emissions related to material extraction and manufacturing of construction products are estimated at $5-12 \%$ of total national greenhouse gas (GHG) emissions in the EU [5]. Furthermore, the material requirement of buildings currently represents one of the greatest resource use challenges in terms of mass of resources used. Concrete, aggregate materials (sand, gravel and crushed stone) and bricks make up to $90 \%$ (by weight) of all materials used [6].

In this context, looking for alternatives that minimize the extraction of raw materials, incorporate recycled materials and reduce the energy consumption related to the manufacture of construction products is another way to move towards decarbonization and a circular building sector. This approach is addressed by the article written by Cătălina Mihaela Grădinaru, Radu Muntean, Adrian Alexandru Serbănoiu, Vasilică Ciocan and Andrei Burlacu [18]. Focused on the manufacture of concrete, they present how to rationalise its use of natural mineral aggregates and reduce its energy consumption by replacing mineral resources with vegetal waste for non-structural concretes. The exposed ecological concretes substitute $50 \%$ of their mineral aggregate volume, thus reducing the extraction of raw materials, and have mechanical properties used for concrete screeds or for modular elements for buildings closures.

The article written by Carolina Piña Ramírez, Alejandra Vidales Barriguete, Julián García Muñoz, Mercedes del Río Merino and Patricia del Solar Serrano [19] is also focused in the replacement of raw materials for sustainable alternatives. In this case, recycled materials are used as reinforcement of cement mortars used for external continuous coating as a mean to seek new uses for construction and demolition waste from buildings. The explored options were characterized obtaining similar values to those cement mortars reinforced with commercial fibres, so it is a viable way to reduce raw material extraction and energy consumption from manufacture, and reuse construction and demolition waste.

Pilar Mercader-Moyano and Jesús Roldán-Porras [20] go beyond manufacture of materials and explore the greenhouse gas emissions related to the phases related to transportation of materials to the worksite and the construction process, applied to foundations and structures. The variables related to those phases are not contemplated in the sustainability assessment in the Spanish legislation and the results they present show the importance of these variables to be considered when choosing the lower contaminant option.

Apart from the contribution of certain phases of the life cycle, it is important to consider the environmental impact of the whole life cycle of a building. This is the focus of the article written by Patricia González-Vallejo, Radu Muntean, Jaime Solís-Guzmán and Madelyn Marrero [21]. The authors compare the environmental impact of housing projects in Spain and Romania using the OERCO2 tool considering the difference in the constructive solutions for structures in both countries. A total of 24 projects were assessed, differentiated by the material of their structure and according to the type of their foundation. They found that buildings with metallic structures were more economical but more contaminant than reinforced concrete, and they ranked the impact of the materials being metal, concrete, cement and ceramic products those with greater environmental impact.

One of the circular economy principles regarding materials is related to their durability. This concept is also related to the economic investment for the replacement of the material or construction product. These aspects should be carefully taken into account especially when working on social 
housing, as their inhabitants are economically, and frequently energy, vulnerable. The article written by Antonio Dominguez-Delgado, Helena Domínguez-Torres and Carlos-Antonio Domínguez-Torres [22] studies not only the energy impact but also the economic one of cool roof constructive solutions through their life cycle in order to evaluate their performance over time as roofs are elements continuously exposed to outdoor climate conditions affecting to the durability of the solution.

Ernesto Antonini, Andrea Boeri, Massimo Lauria and Francesca Giglio also studied durability as an indicator for circular technologies, added to the reversibility of such technologies as design for disassembly is one of the principles of the circular design approach [23]. As the authors indicate "no clear definitions are yet available to link these concepts to indicators suitable for measuring Circular Economy and, specifically, Circular Building Technologies", so they discuss whether reversibility and durability may represent suitable indicators in order to promote the circular assessment of construction technologies, providing useful assessment tools to designers to assist their choices early.

A circular building sector must optimise the use of resources and result in zero waste to landfill. The measures are based on incorporating recycled content and reducing resource waste in the manufacturing process of construction products; minimise the use of new materials, select environmental-friendly construction products, and establish an adequate construction and demolition waste (CDW) management in order to recover quality materials, as CDW is the largest waste stream in EU [17,24-26]. In this context, design for disassembly, one pillar of the circular economy, includes the reduction of CDW as it promotes that buildings and products are designed intentionally for material recovery, value retention and meaningful next use [10].

In this sense, Eduardo Vázquez-López, Federico Garzia, Roberta Pernetti, Jaime Solís-Guzmán and Madelyn Marrero [27] analyse the costs that imply the selective dismantling and waste management which also have a repercussion on the environmental performance of a demolition project. They develop a method to calculate the end-of-life cost through the quantification of demolished materials considering demolition, load, transport and waste management costs. They found that demolition cost was the weight factor and it was mostly due to foundation and structure demolition. Compared to the life cycle cost, the end-of-life cost represents approximately $5 \%$ of the total.

CDW also has to be considered when executing refurbishments in order to update existing building to current legislative requirements. This is the focus of the article written by Begoña Blandón, Luís Palmero and Giacomo di Ruocco [28]. The authors studied the CDW management impact on interventions destinated to repopulate the abandoned rural areas as these areas do not count with the facilities for waste management of the cities, and repopulating the rural areas is another way to move towards decarbonization and circular economy as it reuses and revalue existing built environments. The authors analysed interventions carried out in recent years, reviewed the existing European management protocols specifying their application to Mediterranean popular housing and presented a representative case in order to be conscious about the existing reality regarding the destiny of the CDW in the rural environment.

However, users are also participants on the sustainability of the building stock and the built environment, and they have an important role so tools are needed to transmit, in an understandable manner, how their decisions related to buildings can be sustainable. The article written by Milagrosa Borrallo-Jiménez, Maria Lopez de Asiain, Rafael Herrera-Limones and María Lumbreras Arcos [29] defines a method for the development of tools able to transmit to society scientific knowledge related to sustainability, evaluating the environmental impact of their actions in order to actively involve the actors towards a more sustainable built environment. They present a specific tool experimentally developed for the context of Seville prioritizing communicative actions in order to reach citizens and professionals, but also researchers in the building sector.

The participatory dimension not only has an influence on the built properties of the persons; it can go beyond and be applied to the urban regeneration actions and projects, as shown in the article written by Maria Lopez De Asiaín and Vicente Díaz-García [30]. The authors reviewed the participatory dimension of different urban regeneration actions carried out in Spain and the impact of 
this dimension on the results obtained by environmental, economic and social urban improvements in order to improve the resilience of the cities. They analysed several cases in order to assess their effectiveness and relevance of the actions on the urban development and resilience. From their study, success and fail reasons can be obtained, identifying weaknesses for future participatory actions.

The final reflection of this editorial is that although several cases shown before are thorough and applied to refurbishment, which is important as is a mean to reuse and revalue the existing buildings, the principles of decarbonization and circular economy must be incorporated at the very early stages of building and urban design. In this context, environmental assessment schemes are playing an important role moving the building sector towards its sustainability. The article written by María M. Serrano-Baena, Paula Triviño-Tarradas, Carlos Ruiz-Díaz and Rafael E. Hidalgo Fernández [31] analyses the implications of the BREEAM scheme on the design of hotels for the Spanish context. They present seven case studies and the measures implemented in order to achieve the scheme targets and conclude that although considering the requirements for getting a good environmental assessment may limit the hotel design, it is easier implemented at the early design stage so these limitations can be reduced.

Author Contributions: Conceptualization and methodology, P.M.-M.; investigation and writing—original draft preparation, P.M.E.; writing-review and editing and supervision, P.M.-M. All authors have read and agreed to the published version of the manuscript.

Funding: This research received no external funding.

Acknowledgments: We are grateful to the authors of the contributions to this special issue for their valuable research towards a more decarbonized and circular building sector.

Conflicts of Interest: The authors declare no conflict of interest.

\section{References}

1. European Commission. A Clean Planet for All. A European Strategic Long-Term Vision for a Prosperous, Modern, Competitive and Climate Neutral Economy; Communication from the Commission COM (2018) 773 final; European Commission: Brussels, Belgium, 2018.

2. European Commission. The European Green Deal; Communication from the Commission COM (2019) 640 final; European Commission: Brussels, Belgium, 2019.

3. European Commission. Clean Energy for All Europeans; Communication from the Commission COM (2016) 860 final; European Commission: Brussels, Belgium, 2016.

4. European Commission. Sustainable Products in a Circular Economy-towards an EU Product Policy Framework contributing to the Circular Economy; Commission Staff Working Document SWD (2019) 91 final; European Commission: Brussels, Belgium, 2019.

5. European Commission. A New Circular Economy Action Plan: For a Cleaner and More Competitive Europe; COM (2020) 98 final; European Commission: Brussels, Belgium, 2020.

6. Herczeg, M.; McKinnon, D.; Milios, L.; Bakas, I.; Klaassens, E.; Svatikova, K.; Widerberg, O. Resource Efficiency in the Building Sector; DG Environment FEA91117; Ecorys: Rotterdam, The Netherlands, 2014.

7. MacArthur Foundation. Circular Economy Reports \& Publications from the Ellen MacArthur Foundation. Available online: https://www.ellenmacarthurfoundation.org/assets/downloads/publications/ EllenMacArthurFoundation_Growth-Within_July15.pdf (accessed on 15 July 2020).

8. European Commission. Closing the Loop-An EU Action Plan for the Circular Economy; Communication from the Commission to the European Parliament, the Council, the European Economic and Social Committee and the Committee of the Regions COM(2015) 614 final; European Commission: Brussels, Belgium, 2015.

9. Pomponi, F.; Moncaster, A. Circular economy for the built environment: A research framework. J. Clean. Prod. 2017, 143, 710-718. [CrossRef]

10. Faculty of Architecture and the Built Environment, Delft University of Technology. Circular Built Environment. 2020. Available online: https://www.tudelft.nl/en/architecture-and-the-built-environment/research/researchthemes/circular-built-environment/ (accessed on 10 June 2020).

11. European Commission. Renovation Wave. Energy. Available online: https:/ec.europa.eu/energy/topics/ energy-efficiency/energy-efficient-buildings/renovation-wave_en (accessed on 8 June 2020). 
12. European Commission. An EU Strategy on Heating and Cooling; Communication from the European Commission COM (2016) 51 final; European Commission: Brussles, Belgium, 2016.

13. European Commission. Impact Assessment Accompanying the Document Proposal for a Directive of the European Parliament and of the Council; Commission Staff Working Document SWD (2016) 414 final; European Commission: Brussels, Belgium, 2016.

14. European Commission. Commission Recommendation (EU) 2019/1019 of 7 June 2019 on building modernisation. Off. J. Eur. Union 2019, 165, 70-128.

15. López-Mesa, B.; Monzón-Chavarrías, M.; Espinosa-Fernández, A. Energy Retrofit of Social Housing with Cultural Value in Spain: Analysis of Strategies Conserving the Original Image vs. Coordinating Its Modification. Sustainability 2020, 12, 5579. [CrossRef]

16. Velasco-Gómez, E.; Tejero-González, A.; Jorge-Rico, J.; Rey-Martínez, F.J. Experimental Investigation of the Potential of a New Fabric-Based Evaporative Cooling Pad. Sustainability 2020, 12, 7070. [CrossRef]

17. European Commission. Resource Efficiency Opportunities in the Building Sector; Communication from the Commission COM (2014) 445 final; European Commission: Brussels, Belgium, 2014.

18. Grădinaru, C.M.; Muntean, R.; Șerbănoiu, A.A.; Ciocan, V.; Burlacu, A. Sustainable Development of Human Society in Terms of Natural Depleting Resources Preservation Using Natural Renewable Raw Materials in a Novel Ecological Material Production. Sustainability 2020, 12, 2651. [CrossRef]

19. Ramírez, C.P.; Barriguete, A.V.; Muñoz, J.G.; Merino, M.d.; Serrano, P.d. Ecofibers for the Reinforcement of Cement Mortars for Coating Promoting the Circular Economy. Sustainability 2020, 12, 2835. [CrossRef]

20. Mercader-Moyano, P.; Roldán-Porras, J. Evaluating Environmental Impact in Foundations and Structures through Disaggregated Models: Towards the Decarbonisation of the Construction Sector. Sustainability 2020, 12, 5150. [CrossRef]

21. González-Vallejo, P.; Muntean, R.; Solís-Guzmán, J.; Marrero, M. Carbon Footprint of Dwelling Construction in Romania and Spain. A Comparative Analysis with the OERCO2 Tool. Sustainability 2020, 12, 6745. [CrossRef]

22. Dominguez-Delgado, A.; Dominguez-Torres, H.; Dominguez-Torres, C. Energy and Economic Life Cycle Assessment of Cool Roofs Applied to the Refurbishment of Social Housing in Southern Spain. Sustainability 2020, 12, 5602. [CrossRef]

23. Antonini, E.; Boeri, A.; Lauria, M.; Giglio, F. Reversibility and durability as potential indicators for Circular building Technologies. Sustainability 2020, 12, 7659. [CrossRef]

24. European Union. Level(s)-A common EU framework of core sustainability indicators for office and residential buildings. Parts 1 and 2: Introduction to Level(s) and how it works. JCR Tech. Rep. 2017. [CrossRef]

25. European Commission. Circular Economy Principles for Buildings Design. 2020. Available online: https://ec.europa.eu/docsroom/documents/39984 (accessed on 15 August 2020).

26. Hertwich, E.; Lifset, R.; Pauliuk, S.; Heeren, N. Resource Efficiency and Climate Change: Material Efficiency Strategies for a Low-Carbon Future; Report of the International Resource Panel 978-92-807-3771-4; United Nations Environment Programme: Nairobi, Kenya, 2020.

27. Vázquez-López, E.; Garzia, F.; Pernetti, R.; Solís-Guzmán, J.; Marrero, M. Assessment Model of End-of-Life Costs and Waste Quantification in Selective Demolitions: Case Studies of Nearly Zero-Energy Buildings. Sustainability 2020, 12, 6255. [CrossRef]

28. Blandón, B.; Palmero, L.; di Ruocco, G. The Revaluation of Uninhabited Popular Patrimony under Environmental and Sustainability Parameters. Sustainability 2020, 12, 5629. [CrossRef]

29. Borrallo-Jiménez, M.; LopezdeAsiaín, M.; Herrera-Limones, R.; Arcos, M.L. Towards a Circular Economy for the City of Seville: The Method for Developing a Guide for a More Sustainable Architecture and Urbanism (GAUS). Sustainability 2020, 12, 7421. [CrossRef]

30. LopezDeAsiain, M.; Díaz-García, V. The Importance of the Participatory Dimension in Urban Resilience Improvement Processes. Sustainability 2020, 12, 7305. [CrossRef]

31. Serrano-Baena, M.M.; Triviño-Tarradas, P.; Ruíz-Díaz, C.; Rafael, E.; Fernández, H. Implications of BREEAM Sustainability Assessment on the Design of Hotels. Sustainability 2020, 12, 6550. [CrossRef]

(C) 2020 by the authors. Licensee MDPI, Basel, Switzerland. This article is an open access article distributed under the terms and conditions of the Creative Commons Attribution (CC BY) license (http://creativecommons.org/licenses/by/4.0/). 